\title{
Efeito do Teor Protéico do Concentrado no Consumo de Cana-de-açúcar com Uréia e Ganho de Peso de Novilhas em Crescimento
}

\author{
Armando de Andrade Rodrigues ${ }^{1}$, Pedro Franklin Barbosa ${ }^{1}$
}

\begin{abstract}
RESUMO - O efeito de diferentes suplementos protéicos no consumo de cana-de-açúcar com uréia foi avaliado em novilhas mestiças de Holandês-Zebu, durante a estação seca. Dezoito novilhas com peso médio inicial de $288 \mathrm{~kg}$ e idade variando entre 15 e 22 meses foram suplementadas com farelo de soja ou com concentrado contendo $28,7 \%$ de proteína bruta. A quantidade de suplemento oferecida foi de $1,0 \mathrm{~kg} /$ animal·dia. A cana-de-açúcar com uréia foi fornecida à vontade. As médias dos consumos diários de matéria seca e fibra em detergente neutro de cana-de-açúcar com uréia, em porcentagem do peso vivo, foram 2,33 e 2,43 e 1,19 e 1,23, respectivamente, para os animais suplementados com farelo de soja ou concentrado contendo $28,7 \%$ de proteína bruta. Os suplementos protéicos não influíram no consumo de matéria seca e fibra em detergente neutro da cana-de-açúcar com uréia. Não houve diferença no ganho de peso entre os tratamentos. As médias de ganho de peso foram 0,39+0,04 e 0,36+0,04 kg/animal·dia, respectivamente, para os animais suplementados com farelo de soja ou com concentrado contendo $28,7 \%$ de proteína bruta.
\end{abstract}

Palavras-chave: bovinos, consumo de fibra, consumo de matéria seca, forragem, ganho de peso, proteína

\section{Effect of Protein Content of the Concentrate on the Intake of Sugar Cane with Urea and Weight Gain by Growing Heifers}

\begin{abstract}
The effect of different protein supplements on intake of sugar cane with urea by crossbred Holstein-Zebu heifers was evaluated during 12 weeks in the dry season. Eighteen heifers, averaging initial weight of $288 \mathrm{~kg}$ and age ranging from 15 to 22 months, were supplemented with soybean meal or concentrate with $28.7 \%$ crude protein. The amount of supplement fed was $1.0 \mathrm{~kg} /$ animal-day. Sugar cane with urea was fed ad libitum. The average intake of dry matter and neutral detergent fiber of sugar cane with urea in percent of live weight were 2.33 and $2.43 ; 1.19$ and 1.23 for the animals supplemented with soybean meal or concentrate with $28.7 \%$ crude protein, respectively. The protein supplements did not affect intake of dry matter and neutral detergent fiber of sugar cane with urea. The supplements did not affect heifers weight gain. The average daily weight gains were $.39+.04$ and $.36+.04 \mathrm{~kg} / \mathrm{animal} \cdot \mathrm{day}$ for animals supplemented with soybean meal or with concentrate containing $28.7 \%$ crude protein, respectively.
\end{abstract}

Key Words: cattle, fiber intake, dry matter intake, forage, weight gain, protein

\section{Introdução}

O teor de proteína e a baixa digestibilidade da fibra da cana-de-açúcar são fatores que limitam a utilização desta forrageira pelos bovinos.

Nos sistemas de alimentação em que os volumosos são os constituintes principais da dieta, a ingestão voluntária de matéria seca é variável de grande importância para o desempenho animal. Tem sido observado que a suplementação protéica melhora o consumo de forragem (PIMENTEL et al., 1997). Por outro lado, o consumo de matéria seca pelos ruminantes está relacionado com o teor de fibra detergente neutro (FDN) da dieta. A utilização de volumosos com alto teor de FDN ou baixa digestibilidade da fibra pode resultar em elevado tempo de retenção da digesta no rúmen, promovendo diminuição do consumo.
Em dietas com cana-de-açúcar é necessário satisfazer tanto as necessidades de nitrogênio dos microrganismos quanto as necessidades de proteína "by pass" do animal (PRESTON e LENG, 1978). Para satisfazer as necessidades de nitrogênio dos microrganismos, tem-se utilizado a uréia, enquanto para atender às necessidades de proteína do animal, têm sido comumente utilizado farelos, contendo desde, aproximadamente, $13 \%$ de proteína bruta (p.ex. farelo de arroz) até, aproximadamente, $50 \%$ de proteína bruta (farelo de soja). Além do teor de proteína, o potencial dos diferentes suplementos em fornecer nutrientes sobrepassantes difere entre os mesmos.

Segundo ODDY et al. (1997), a resposta em crescimento pelos ruminantes, devido à suplementação com proteína que escapa a degradação ruminal é variável. Os resultados obtidos por esses autores 
mostram que ocorre aumento do fluxo e oxidação de aminoácidos e da taxa de utilização de glicose, e esta relação é influenciada pelo histórico alimentar prévio (peso em determinada idade) e pela disponibilidade de energia da dieta ou de reservas corporais.

Embora a literatura mostre que a suplementação protéica de dietas à base de forragens tropicais proporciona melhoria no ganho de peso, os dados publicados relativos ao efeito de diferentes suplementos (composição dos mesmos, potencial em fornecer nutrientes sobrepassantes e níveis de proteína) são limitados.

O objetivo deste trabalho foi verificar o efeito do teor protéico do concentrado sobre o consumo de cana-de-açúcar e uréia e ganho de peso por novilhas em crescimento.

\section{Material e Métodos}

O trabalho foi desenvolvido no Centro de Pesquisa de Pecuária do Sudeste, localizado em São Carlos - SP, região central do Estado de São Paulo. Foram utilizadas 18 novilhas mestiças de Holandês-Zebu, com peso médio inicial de $288 \mathrm{~kg}$ e idade variando entre 15 e 22 meses. Os animais foram distribuídos em blocos ao acaso em função do peso vivo e idade. Foram comparados dois suplementos em dieta à base de canade-açúcar e uréia: 1) 1,0 kg de farelo de soja com $50,2 \%$ de $\mathrm{PB}$ e 2) $1,0 \mathrm{~kg}$ de concentrado contendo milho (50\%), farelo de soja (47,5\%) e calcário calcítico (2,5\%), com $28,7 \%$ de proteína bruta. A variedade de cana-de-açúcar utilizada foi a CB 47-355, sendo utilizado $1 \%$ de uréia (proporção uréia:sulfato de amônio de 9:1) na cana-de-açúcar na base de matéria original, para corrigir a deficiência de nitrogênio para os microrganismos de rúmen. $\mathrm{O}$ farelo de soja e o milho foram escolhidos para entrar na composição do concentrado em função de seus potenciais em fornecer nutrientes que sobrepassam o rúmen, conforme potencial relativo de diferentes alimentos em fornecer proteína e compostos gluconeogênicos pós-rúmen, mencionado por PRESTON e LENG (1984). Segundo CAMPOS et al. (1995), o percentual de proteína não degradável no rúmen do farelo de soja extraído por solvente é de $33 \%$. Os animais foram mantidos estabulados em baias individuais, com parte coberta contendo cochos para fornecimento dos alimentos e bebedouro. Os suplementos foram fornecidos duas vezes ao dia em cochos separados da cana-deaçúcar, que foi fornecida ad libitum uma vez ao dia pela manhã. Separadamente forneceu-se mistura mineral à vontade. Os consumos foram avaliados durante 12 semanas e os animais foram pesados a intervalos de 14 dias, sem jejum, durante um período de 112 dias. As médias de consumo e ganho de peso foram submetidas à análise de variância.

\section{Resultados e Discussão}

A variedade de cana-de-açúcar utilizada apresentou os seguintes teores: $52,5 \%$ de FDN e $1,4 \%$ de PB. Após a adição de uréia, os conteúdos de FDN e PB foram, respectivamente, 51,1 e 12,1\%. O teor de BRIX foi de 16,8. A relação FDN/BRIX foi 3,1, cujo valor indica que a qualidade desta variedade é inferior quando comparada com outras variedades mais adequadas para alimentação de bovinos (RODRIGUES et al.,1997). Segundo GOODING (1982), é necessário que a cana-de-açúcar utilizada para a alimentação animal apresente relação FDN/açúcar baixa ou inversamente relação açúcar/fibra mais alta. Esse autor comenta que variedades com menor teor de fibra permitem maior consumo de açúcar que variedades com igual teor de açúcar ou até mesmo variedades com teor de açúcar pouco maior, mas que contenham teor de fibra mais elevado.

A utilização de concentrado ou farelo de soja contendo teores protéicos diferentes não apresentou efeito significativo sobre o consumo de matéria seca de cana-de-açúcar e uréia em porcentagem do peso vivo (Tabela 1). Trabalhando com diferentes níveis de farelo de soja (zero até 600 gramas), GUTHRIE e WAGNER (1988) verificaram incremento no consumo e na digestibilidade, à medida que se aumentavam os níveis de farelo de soja. Concluíram que níveis mais elevados de farelo de soja deveriam ser testados incluindo outros tipos de forragem.

Mesmo considerando que as fontes de proteína verdadeira são mais eficientes em aumentar o consumo, o resultado obtido, em parte, pode ser explicado pelo fato de não ter havido deficiência de nitrogênio não-protéico para os microrganismos e, provavelmente, pela baixa digestibilidade da fibra, característica verificada por RODRIGUES et al. (1992b). Os consumos de uréia foram de 205 e $225 \mathrm{~g} /$ animal/dia para os animais que receberam o concentrado ou o farelo de soja, respectivamente. Os resultados obtidos neste trabalho estão de acordo com os resultados obtidos por RESENDE et al. (1994) e DUTRA et al. (1996), os quais só verificaram aumento da ingestão de matéria seca quando houve decréscimo na quantidade de FDN da dieta. Todavia, PIMENTEL et al. 
Rev. bras. zootec.

Tabela 1- Consumo médio diário de matéria seca (MS) e fibra em detergente neutro (FDN) e desempenho de novilhas alimentadas com cana-de-açúcar, uréia e concentrado protéico

Table 1- $\quad$ Average daily intake of dry matter (DM) and neutral detergent fiber (NDF) and performance of heifers fed sugar cane, urea and protein concentrate

\begin{tabular}{|c|c|c|}
\hline \multirow[t]{2}{*}{ Item } & \multicolumn{2}{|c|}{$\begin{array}{l}\text { Teor protéico do concentrado } \\
\text { Protein level of concentrate }\end{array}$} \\
\hline & $50,2 \%$ & $28,7 \%$ \\
\hline Consumo MS de cana-de-açúcar (\% PV) & 2,33 & 2,43 \\
\hline DM intake of sugar cane $(\% L W)$ & & \\
\hline Consumo MS de concentrado (\% PV) & 0,26 & 0,30 \\
\hline DM intake of concentrate (\% LW) & & \\
\hline Consumo MS total (\% PV) & 2,59 & 2,73 \\
\hline Total DM intake $(\% L W)$ & & \\
\hline $\begin{array}{l}\text { Consumo MS de cana-de-açúcar }\left(\mathrm{g} / \mathrm{kg}^{0,75}\right) \\
\text { DM intake of sugar cane }\left(g / \mathrm{kg}^{75}\right)\end{array}$ & 97,67 & 98,16 \\
\hline $\begin{array}{l}\text { Consumo MS de concentrado }\left(\mathrm{g} / \mathrm{kg}^{0,75}\right) \\
\text { DM intake of concentrate }\left(g / \mathrm{kg}^{75}\right)\end{array}$ & 11,65 & 12,51 \\
\hline $\begin{array}{l}\text { Consumo MS total }\left(\mathrm{g} / \mathrm{kg}^{0,75}\right) \\
\text { Total DM intake }\left(\mathrm{g} / \mathrm{kg}^{75}\right)\end{array}$ & 109,32 & 110,67 \\
\hline Consumo FDN de cana-de-açúcar (\% PV) & 1,19 & 1,23 \\
\hline $\begin{array}{l}\text { NDF intake of sugar cane }(\% L W) \\
\text { Consumo FDN de concentrado }(\% \mathrm{PV})\end{array}$ & 0,02 & 0,02 \\
\hline NDF intake of concentrate $(\% \mathrm{LW})$ & & \\
\hline $\begin{array}{l}\text { Consumo FDN total }(\% \mathrm{PV}) \\
\text { Total } N D F \text { intake }(\% L W)\end{array}$ & 1,21 & 1,25 \\
\hline $\begin{array}{l}\text { Consumo FDN de cana-de-açúcar }\left(\mathrm{g} / \mathrm{kg}^{0,75}\right) \\
\text { NDF intake of sugar cane }\left(\mathrm{g} / \mathrm{kg}^{75}\right)\end{array}$ & 49,87 & 50,07 \\
\hline $\begin{array}{l}\text { Consumo FDN de concentrado }\left(\mathrm{g} / \mathrm{kg}^{0,75}\right) \\
\text { NDF intake of concentrate }\left(\mathrm{g} / \mathrm{kg}^{.75}\right)\end{array}$ & 1,03 & 1,14 \\
\hline $\begin{array}{l}\text { Consumo FDN total }\left(\mathrm{g} / \mathrm{kg}^{0,75}\right) \\
\text { Total NDF intake }\left(\mathrm{g} / \mathrm{kg}^{.75}\right)\end{array}$ & 50,90 & 51,21 \\
\hline Peso inicial $(\mathrm{kg})$ & 305,0 & 268,4 \\
\hline Peso final $(\mathrm{kg})$ & 350,2 & 310,1 \\
\hline $\begin{array}{l}\text { Final weight } \\
\text { Ganho diário (kg/animal·dia) }\end{array}$ & 0,39 & 0,36 \\
\hline
\end{tabular}

(1997) verificaram aumento no consumo de matéria seca de $31,3 \%$ para silagem de sorgo e de $19,4 \%$ para silagem de milho, quando forneceram $20 \%$ de farelo de soja na matéria seca da dieta. Os consumos de matéria seca do presente trabalho foram superiores aos verificados por RODRIGUES et al. (1994), que observaram variação de consumo de cana-de-açúcar e uréia de 1,8 a $2,0 \%$ do peso vivo.

As médias de ingestão de FDN de cana-deaçúcar e da dieta total, expressas em \% do peso vivo, foram de 1,19 e $1,23 \%$ e 1,21 e $1,25 \%$, respectivamente, para os animais suplementados com farelo de soja ou com concentrado contendo $28,7 \%$ de proteína, as quais são semelhantes ao valor mencionado por MERTENS (1992), o qual observou que a ingestão ótima de FDN por vacas em lactação foi de 1,2\%. Apesar de os níveis de proteína dos concentrados serem diferentes, não houve efeito na ingestão de
FDN em porcentagem do peso vivo. Isto mostra que a ingestão voluntária de FDN em porcentagem do peso vivo foi limitada pelo enchimento físico do trato gastrintestinal. Resultado semelhante foi encontrado por RESENDE et al. (1994), que também não encontraram diferença na ingestão de FDN.

Não houve diferença significativa entre os ganhos médios diários de peso. Os ganhos foram $0,39 \mathrm{~kg} /$ animal dia, quando suplementados com farelo de soja, e $0,36 \mathrm{~kg} /$ animal·dia, quando suplementados com concentrado.

Deve ser salientado que o farelo de soja, sendo de origem vegetal, contém amido que pode ser utilizado como precursor de glicose, devido ao fato de que o aquecimento durante o manufaturamento para extração de óleo pode ter conferido ao mesmo alguma proteção em relação à degradação ruminal. Esta característica pode ter contribuído para a ausência de 
diferença no ganho de peso entre os tratamentos e ainda explicar, em alguns casos, o fato de se considerar a resposta em ganho de peso, unicamente em razão do fornecimento de proteína. Estes ganhos são inferiores aos obtidos por RODRIGUES et al. (1992a). Os baixos ganhos obtidos podem ser atribuídos, em parte, a dois aspectos; o primeiro é que a qualidade da cana-de-açúcar pode ter limitado o consumo de energia digestível, tendo em vista que a digestibilidade da fibra da cana-de-açúcar é baixa, e o segundo é que os animais se apresentavam em boas condições corporais por ocasião do início do experimento, não havendo, conseqüentemente, ganho compensatório, o que, no entanto, pode ter ocorrido em outros trabalhos. Por outro lado, estes ganhos são superiores aos observados por FURTADO et al. (1991), que suplementaram dietas de cana-de-açúcar para novilhas mestiças de holandêszebu, de idade e peso semelhantes aos deste trabalho, com quantidade maior de suplemento $(2,0 \mathrm{~kg}$ de farelo de trigo/animal·dia), comparativamente à quantidade de suplemento utilizado neste trabalho $(1,0 \mathrm{~kg} / \mathrm{anima} / \mathrm{dia})$.

\section{Conclusões}

Os teores protéicos dos concentrados não influíram no consumo de matéria seca e fibra em detergente neutro da cana-de-açúcar e uréia, em porcentagem do peso vivo das novilhas.

Em dietas com potencial de ganho de peso limitado, é possível utilizar suplementos com menor teor de proteína.

\section{Referências Bibliográficas}

CAMPOS, O. F. de., LIZIEIRE, R.S., DAYRELL, M. de S. et al. 1995. Características e composição de alguns alimentos concentrados utilizados na alimentação de bovinos de leite. Coronel Pacheco, MG: EMBRAPA-CNPGL-ADT, 29p. (EMBRAPA-CNPGL. Circular Técnica, 38).

DUTRA, A.R., QUEIROZ, A.C., PEREIRA, J.C. et al. Efeitos dos níveis de proteína sobre o consumo e digestão dos nutrientes em novilhos. In: REUNIÃO ANUAL DA SOCIEDADE BRASILEIRA DE ZOOTECNIA, 33, 1996, Fortaleza. Anais...Fortaleza: SBZ, p.6-8, 1996.

FURTADO, D. A., CAMPOS, J., COELHO DA SILVA, J. F. et al. 1991. Farelo de trigo como suplemento energéticoprotéico para cana-de-açúcar (Saccharum officinarum, L.) e silagem de milho. R. Soc. Bras. Zootec., 20(3):209-217.

GOODING, E.G.B. 1982. Effect of quality of cane on its value as livestock feed. Trop. Anim. Prod., 7(1):72-91.
GUTHRIE, M. J., WAGNER, D. G. 1988. Influence of protein or grain supplementation and increasing levels of soybean meal on intake, utilization and passage rate of prairie hay in beef steers and heifers. J. Anim. Sci., 66(6):1529-1537.

MERTENS, D.R. Análise da fibra e sua utilização na avaliação de alimentos e formulação de rações. In: REUNIÃO ANUAL DA SOCIEDADE BRASILEIRA DE ZOOTECNIA, 29, 1992, Lavras. Palestras do Simpósio Internacional de Ruminantes. Anais...Lavras: SBZ, p.188-219, 1992.

ODDY, V. H., EDWARDS, S. R., WARREN, H.M. et al.1997. Interrelationships between amino acid and glucose metabolism in lambs of different dietary history supplemented with rumen escape protein. J. Agric. Sci., 128(1):105-116.

PIMENTEL, J.J.O., SILVA, J.F.C., VALADARES FILHO, S.C. et al.Efeito da suplementação protéica no valor nutritivo de silagens de milho e de sorgo. In: REUNIÃO ANUAL DA SOCIEDADE BRASILEIRA DE ZOOTECNIA, 34, 1997, Juiz de Fora. Anais...Juiz de Fora: SBZ, p.184-186, 1997.

PRESTON, T.R., LENG, R.A. 1978. Sugar cane as cattle feed. World Animal Review, 27:7-12.

PRESTON, T.R., LENG, R.A. 1984. Supplementation of diets based on fibrous residues and by-products. In: Straw and other fibrous by-products as feed. Sundstol, F. \& Owen, E. ed., Elsevier, Amsterdam, p.373-413.

RESENDE, F.D., QUEIROZ, A.C., FONTES, C.A.A. et al. 1994. Rações com diferentes níveis de fibra em detergente neutro na alimentação de bovídeos em confinamento. $R$. Soc. Bras. Zootec., 23(3):366-376.

RODRIGUES, A. de A. PRIMAVESI, O. ESTEVES, S.N. 1997. Efeito da qualidade de variedades de cana-de-açúcar sobre seu valor como alimento para bovinos. Pesq. Agrop. Bras., 32(12):1333-1338.

RODRIGUES, A. de A., TORRES, R.A., CAMPOS, O.F. et al. 1994. Uréia e sulfato de cálcio para bovinos alimentados com cana-de-açúcar. R. Soc. Bras. Zootec., 23(4):585-594.

RODRIGUES, A. de A., TORRES, R. A., ESTEVES, S. N. 1992a. Efeito da suplementação com nitrogênio e enxofre no consumo e ganho de peso por novilhas alimentadas com canade-açúcar. ARS Veterinária, 8(2):148-155.

RODRIGUES, A. de A., VIEIRA, P.F., TORRES, R.A. et al. 1992b. Efeito da uréia e sulfato de cálcio na digestibilidade de cana-de-açúcar por ruminantes. Pesq. Agrop. Bras., 27(10):1421-1427.
Recebido em: 28/04/98 Aceito em: 24/09/98 